\title{
TSLP/TSLPR promote angiogenesis following ischemic stroke via activation of the PI3K/AKT pathway
}

\author{
XIANG YU, YI PENG, HUI LIANG, KE FU, ZHIHONG ZHAO, CHUN XIE, LIN ZHOU and KANGNAN ZHANG
}

Department of Internal Neurology, Hunan Provincial People's Hospital, Changsha, Hunan 410005, P.R. China

Received February 16, 2017; Accepted October 10, 2017

DOI: $10.3892 / \mathrm{mmr} .2017 .8217$

\begin{abstract}
The current study aimed to investigate the effects of the thymic stromal lymphopoietin (TSLP)/TSLP receptor (TSLPR) on angiogenesis following ischemic stroke in vivo and in vitro. Furthermore, whether the phosphatidylinositol 3 kinase $(\mathrm{PI} 3 \mathrm{~K}) /$ protein kinase $\mathrm{B}(\mathrm{AKT})$ pathway mediates the effects of TSLP/TSLPR on angiogenesis was explored. A rat middle cerebral artery occlusion (MCAO) model was established, and it was demonstrated that the expression levels of TSLP and TSLPR were significantly increased in the infarct area between 12 and $72 \mathrm{~h}$ after MCAO, as determined by ELISA and western blot analyses. TSLP injection was revealed to upregulate vascular endothelial growth factor A (VEGFA) and angiopoietin 2 (Ang-2) expression levels in the infarct area following MCAO, as determined by western blot analysis. An in vitro MCAO model was constructed by exposing human umbilical vein endothelial cells (HUVECs) to oxygen-glucose deprivation (OGD). It was revealed that the expression levels of TSLP and TSLPR were significantly increased in HUVECs subjected to OGD. TSLP treatment was revealed to induce in vitro angiogenesis by promoting cell proliferation and migration, and increasing tube length of OGD-treated HUVECs, as determined by MTT, Transwell-migration and tube formation assays, respectively. Furthermore, it was demonstrated that the PI3K/AKT pathway was activated by TSLP treatment. However, it was revealed that PI3K inhibitor, LY294002, could attenuate the effects of TSLP on in vitro angiogenesis of OGD-treated HUVECs. In conclusion, to the best of our knowledge, this study demonstrated for the first time that TSLP/TSLPR promote angiogenesis following ischemic stroke in vivo and in vitro. Furthermore, it was demonstrated that the effects of TSLP/TSLPR on angiogenesis were, at least partially, mediated via activation of the PI3K/AKT pathway.
\end{abstract}

Correspondence to: Dr Hui Liang, Department of Internal Neurology, Hunan Provincial People's Hospital, 61 Jiefang West Road, Changsha, Hunan 410005, P.R. China

E-mail: hui_liang7599@163.com

Key words: angiogenesis, phosphatidylinositol 3 kinase pathway, stroke, thymic stromal lymphopoietin
TSLP/TSLPR may serve as a potential therapeutic target for ischemic stroke treatment.

\section{Introduction}

Stroke is a life-threatening condition with a high mortality rate and a high risk of subsequent disability $(1,2)$. Ischemic stroke is the most common form of stroke, accounting for $\sim 85 \%$ of the total number of strokes (3). Despite advances in current stroke therapies, many patients do not benefit from conventional treatments.

Ischemic strokes are caused by a blockage of the arteries responsible for the provision of blood to the brain or spinal cord, therefore resulting in critically reduced blood flow to said region(s). Well-functioning collateral circulation has been demonstrated to improve the clinical prognosis following an ischemic stroke (4-6). Angiogenesis is the generation of new blood vessels from pre-existing vasculature (7). A series of studies have revealed that post-ischemic angiogenesis contributes to the improvement in neurological functional recovery following a stroke (8). Therefore, angiogenesis has been suggested to be a promising therapeutic target for ischemic stroke.

Thymic stromal lymphopoietin (TSLP), a member of the interleukin 7 cytokine family, is predominantly produced by epithelial cells, fibroblasts and smooth muscle cells $(9,10)$. TSLP signals via a TSLP receptor (TSLPR), which is widely distributed among a number of different immune cells, such as mast cells, monocytes, dendritic cells and lymphocytes (11-16). Thus, TSLP has been suggested to be involved in the modulation of both innate and adaptive immune responses (17-20). Previously, Xie et al (21) reported that TSLP is able to modulate the biological behavior of vascular endothelial cells in vitro, and is also involved in the angiogenesis of cervical cancer. However, the exact role of TSLP/TSLPR in angiogenesis following ischemic stroke has not previously been investigated.

In the present study, the biological role of TSLP/TSLPR in angiogenesis in rats subjected to middle cerebral artery occlusion (MCAO), and human umbilical vein endothelial cells (HUVECs) subjected to oxygen-glucose deprivation (OGD) were investigated. Furthermore, whether or not the phosphatidylinositol 3 kinase (PI3K)/protein kinase B (AKT) pathway can mediate the effects of TSLP/TSLPR on angiogenesis following ischemic stroke was determined. 


\section{Materials and methods}

Animals. This study was approved by the Ethics Committee of Hunan Provincial People's Hospital (Changsha, China), and all of the experiments performed on animals were performed in compliance with the principles of experimental animal ethics. A total of 48 Sprague-Dawley male rats at the age of 8 weeks, weighing 300-350 g, were obtained from Shanghai SLAC Laboratory Animal Co., Ltd. (Shanghai, China). The rats were maintained under controlled conditions $\left(22 \pm 2^{\circ} \mathrm{C}\right.$; $55 \%$ humidity) with a $12 \mathrm{~h} \mathrm{light/dark} \mathrm{cycle,} \mathrm{and} \mathrm{free} \mathrm{access} \mathrm{to}$ food and fresh water. The permanent middle cerebral artery occlusion (MCAO) model was established in accordance with the Longa et al study (22). Briefly, the rats in the MCAO group were anesthetized via an intraperitoneal injection of $10 \%$ chloral hydrate $(300 \mathrm{mg} / \mathrm{kg}$ intraperitoneal injection). Subsequently, the right common carotid artery was exposed through a $2 \mathrm{~cm}$ midline incision in the neck. To occlude the middle cerebral artery, a 4-0 nylon suture with a silicone tip was inserted into the internal carotid artery until mild resistance was felt. At 6, 12, 24 and $72 \mathrm{~h}$ time intervals following $\mathrm{MCAO}$, the rats were sacrificed via an intraperitoneal injection of pentobarbital (Sigma-Aldrich; Merck KGaA, Darmstadt, Germany). Rats in the sham group were anesthetized and underwent surgery without MCAO. The neurological function of the rats was then tested $2 \mathrm{~h}$ post-MCAO in accordance with the Longa et al study (22), and rats with scores of between one and three were held for further experiments. Human TSLP recombinant protein was sourced from Abnova (Taipei, Taiwan). The MCAO rats ( $\mathrm{n}=6 /$ group) were then given either $10 \mu \mathrm{g}$ of recombinant TSLP or phosphate-buffered saline (PBS) intraperitoneally for $24 \mathrm{~h}$. Subsequently, the rats were sacrificed and cerebral infarct areas were collected.

Cell culture and treatment. HUVECs (American Type Culture Collection, Manassas, VA, USA) were cultured in a RPMI-1640 (Gibco; Thermo Fisher Scientific, Inc., Waltham, MA, USA) supplemented with $10 \%$ fetal calf serum (Gibco; Thermo Fisher Scientific, Inc.) and $100 \mathrm{U} / \mathrm{ml}$ streptomycin/penicillin at $37^{\circ} \mathrm{C}$. Cells cultured under normal conditions were maintained in a humidified atmosphere of $95 \%$ air and $5 \% \mathrm{CO}_{2}$. Cells in the OGD condition were cultured in the RPMI-1640 without glucose, and maintained in a humidified atmosphere of $94 \% \mathrm{~N}_{2}, 1 \% \mathrm{O}_{2}$ and $5 \% \mathrm{CO}_{2}$ for $2 \mathrm{~h}$. Following this, the OGD-treated cells were cultured in the RPMI-1640 with $5.5 \mathrm{mmol} / \mathrm{l}$ glucose under normoxic conditions for reoxygenation for $24 \mathrm{~h}$. The cells subjected to OGD were treated with TSLP at a concentration of $20 \mathrm{ng} / \mathrm{ml}$. LY294002 (50 $\mu \mathrm{M}$; Cell Signaling Technology, Inc., Danvers, MA, USA) was administered in order to suppress the PI3K/AKT pathway.

ELISA. Tissues of the cerebral infarct area and HUVEC cell supernatants were collected, and the concentration of TSLP was then determined by ELISA assay according to the manufacturer's instructions (DTSLP0, R\&D Systems, Inc., Minneapolis, MN, USA).

Western blot analysis. Total proteins were prepared from the cerebral infarct area and HUVEC cells using a Total Protein Extraction kit (Thermo Fisher Scientific, Inc.), and protein
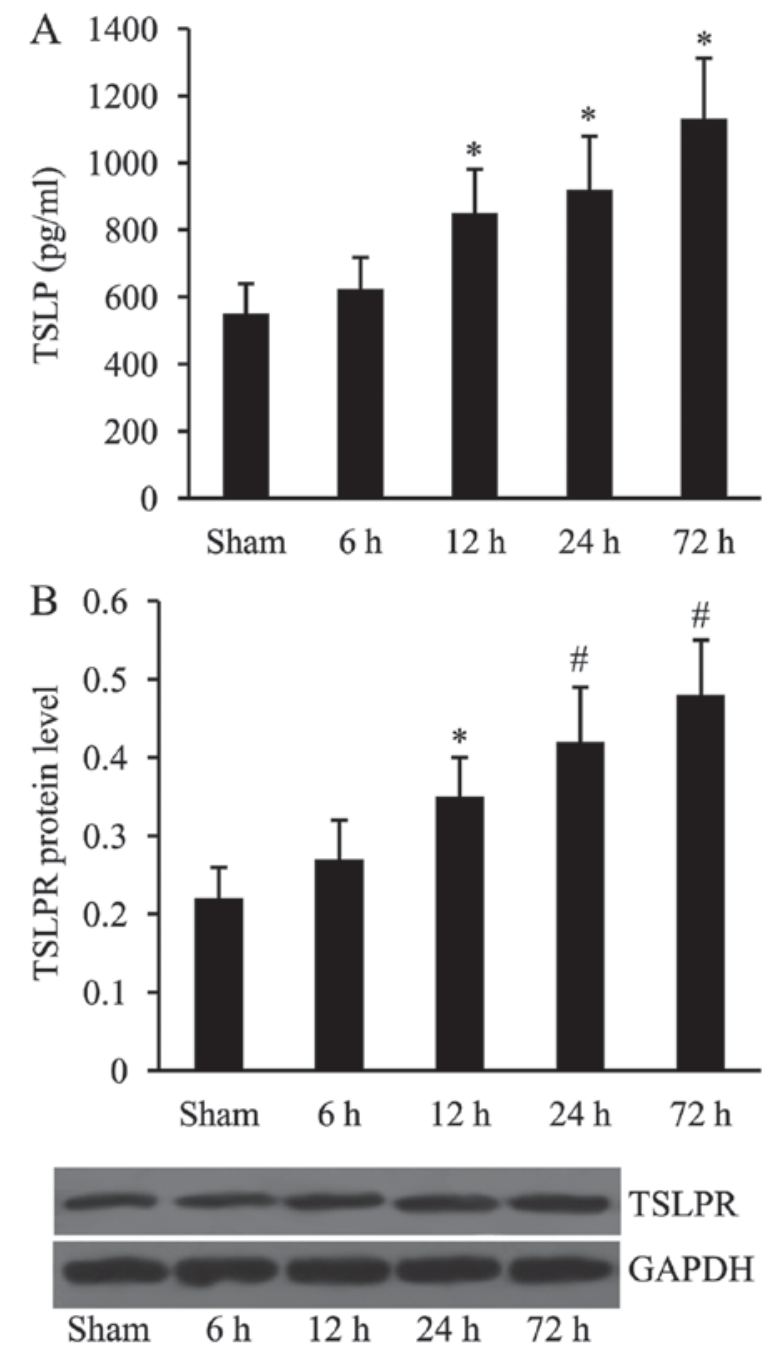

Figure 1. Expression levels of TSLP and TSLPR in the infarct area of rats following MCAO. (A) Expression of TSLP in the infarct area of rats following MCAO and (B) expression of TSLPR in the infarct area of rats following MCAO. $n=3$. ${ }^{\mathrm{P}}<0.05$ and ${ }^{\#} \mathrm{P}<0.01$ vs. sham group. MCAO, middle cerebral artery occlusion; TSLP, thymic stromal lymphopoietin; TSLPR, thymic stromal lymphopoietin receptor.

concentrations were then determined using a Bicinchoninic Acid protein assay (Pierce; Thermo Fisher Scientific, Inc.). Equal masses of protein samples $(50 \mu \mathrm{g})$ were subsequently separated on a $10 \%$ SDS-PAGE gel and electrophoretically transferred to nitrocellulose membranes. Following blocking with Tris-buffered saline $0.1 \%$ Tween (TBST) containing $5 \%$ non-fat milk for $2 \mathrm{~h}$ at room temperature, the membranes were then incubated with the primary antibodies at $4^{\circ} \mathrm{C}$ overnight. The primary antibodies used in these analyses included anti-TSLPR (1:500; sc-517429, Santa Cruz Biotechnology, Inc., Dallas, TX, USA), vascular endothelial growth factor A (VEGFA; 1:800; sc-507, Santa Cruz Biotechnology, Inc.), angiopoietin 2 (Ang-2; 1:400; sc-74402, Santa Cruz Biotechnology, Inc.), phosphorylated AKT (p-AKT; Ser 473 1:400; 12694, Cell Signaling Technology, Inc.), AKT (1:800; 2920, Cell Signaling Technology, Inc.) and GAPDH (1:1,000; sc-47724, Santa Cruz Biotechnology, Inc.). Following washing with TBST, the membranes were further incubated with horseradish peroxidase-conjugated secondary antibody (1:5,000; sc-2005, Santa Cruz Biotechnology, Inc.) 


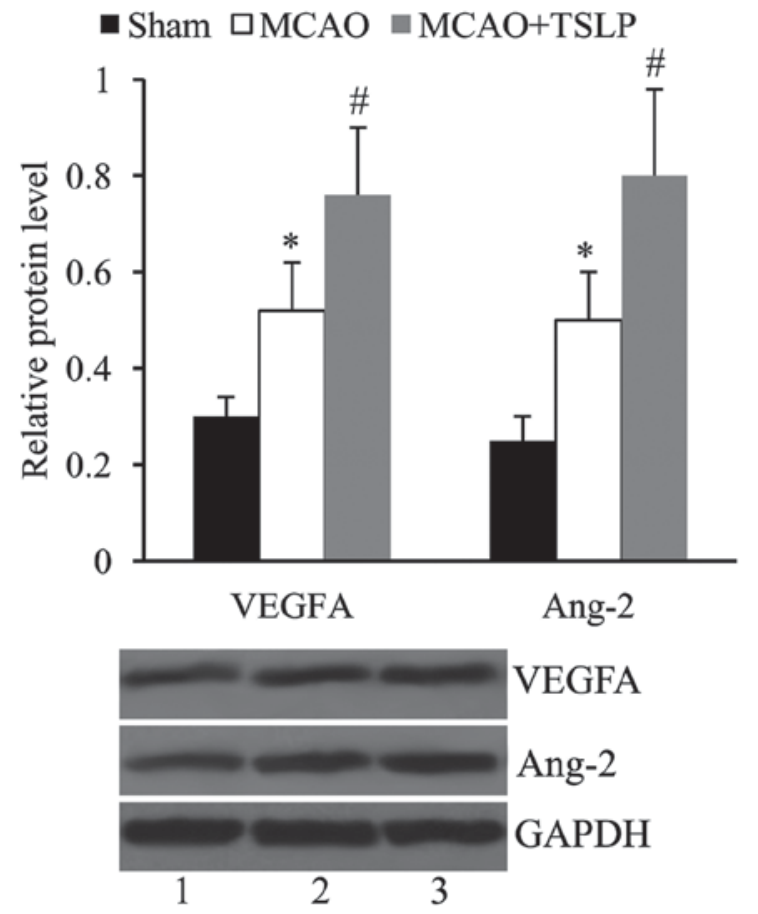

Figure 2. Effect of TSLP $(10 \mu \mathrm{g})$ on VEGFA and Ang-2 expression in the infarct area of rats following MCAO. Lane 1, Sham; lane 2, MCAO; lane 3, MCAO + TSLP. $n=3$. " $\mathrm{P}<0.05$ vs. sham; ${ }^{~} \mathrm{P}<0.05$ vs. MCAO. MCAO, middle cerebral artery occlusion; TSLP, thymic stromal lymphopoietin; VEGFA, vascular endothelial growth factor A; Ang-2, angiopoietin 2.

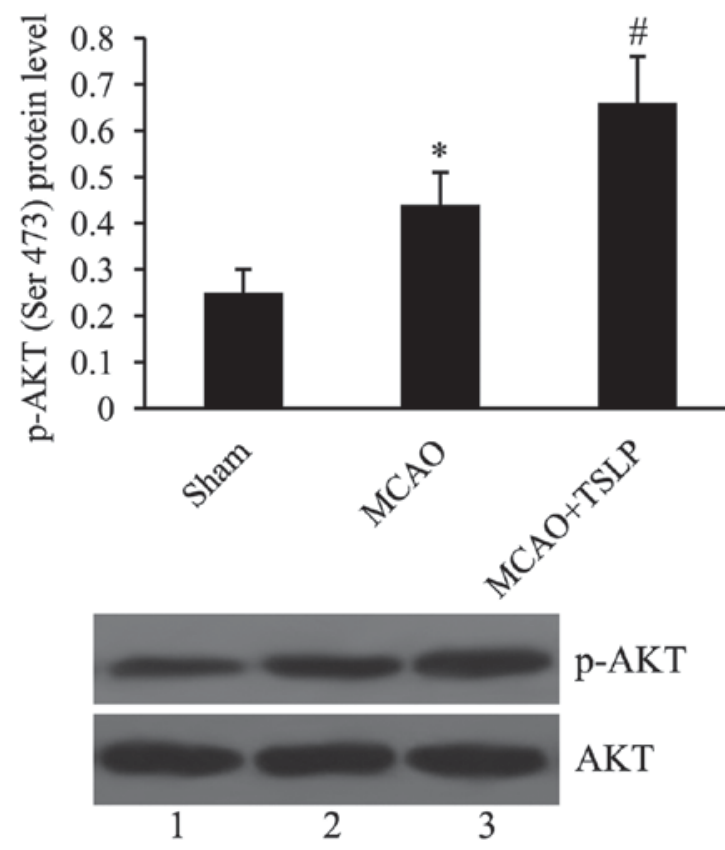

Figure 3. Effect of TSLP on the phosphatidylinositol 3 kinase pathway in the infarct area of rats following MCAO. Akt served as the control. Lane 1 , Sham; lane 2, MCAO; lane 3, MCAO + TSLP. $n=3$. ${ }^{*} \mathrm{P}<0.05$ vs. sham; ${ }^{*} \mathrm{P}<0.05$ vs. MCAO. TSLP, thymic stromal lymphopoietin; MCAO, middle cerebral artery occlusion; AKT, protein kinase B; p-, phosphorylated.

at $37^{\circ} \mathrm{C}$ for $2 \mathrm{~h}$. The target bands were then developed using the super ECL reagent (Thermo Fisher Scientific, Inc.). The density of bands was analyzed using Image-Pro Plus, version 6.0 software (Media Cybernetics, Inc., Rockville, MD, USA).
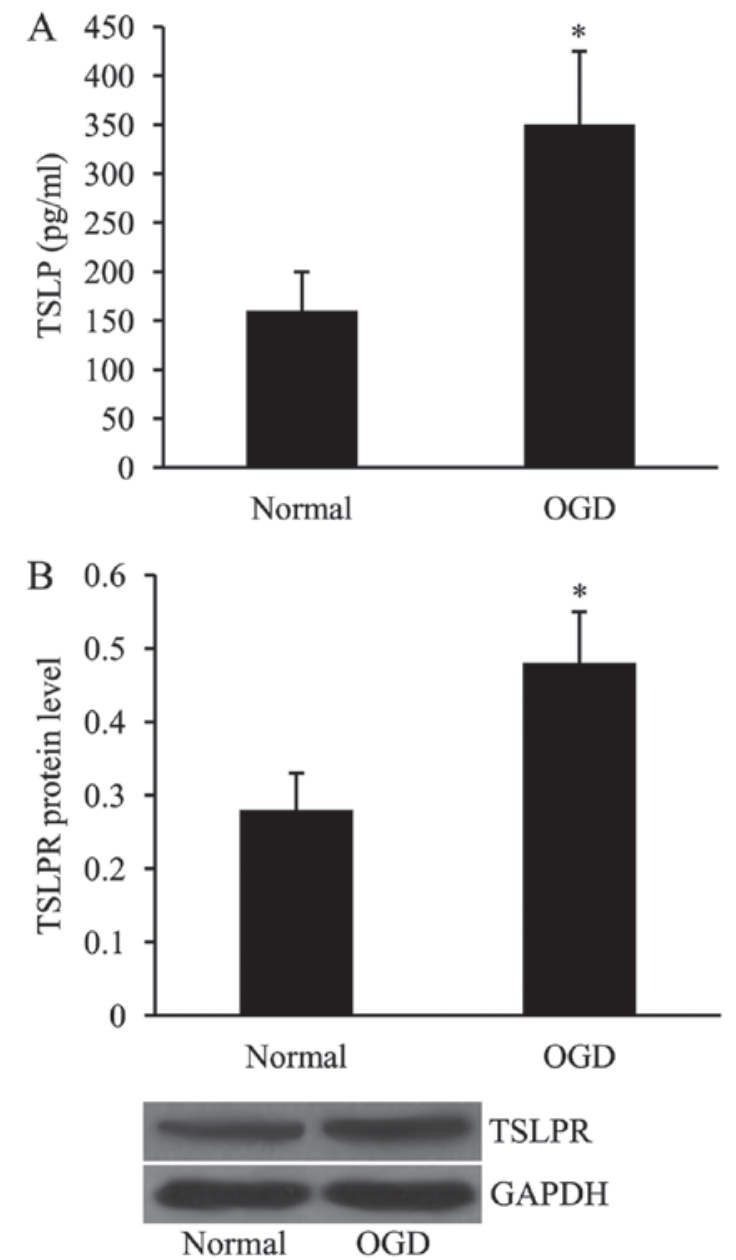

Figure 4. Expression levels of TSLP and TSLPR in HUVECs subjected to OGD. (A) Expression of TSLP in OGD-treated HUVECs and (B) expression of TSLPR in OGD-treated HUVECs. $n=3$. ${ }^{*} \mathrm{P}<0.05$ vs. normal. HUVECs, human umbilical vein endothelial cells; TSLP, thymic stromal lymphopoietin; OGD, oxygen-glucose deprivation; TSLPR, thymic stromal lymphopoietin receptor.

Cell proliferation assay. The MTT Assay Kit was purchased from Beyotime Institute of Biotechnology (Shanghai, China). According to the manufacturer's instructions, $2 \times 10^{3}$ cells were plated into the 96-well plates, and treated with $20 \mathrm{ng} / \mathrm{ml}$ TSLP. The cells were allowed to grow for $12,24,48$ and $72 \mathrm{~h}$ time intervals, and then $10 \mu \mathrm{l}$ MTT solution $(5 \mathrm{mg} / \mathrm{ml})$ was added into each well. Following incubation at $37^{\circ} \mathrm{C}$ for $4 \mathrm{~h}, 10 \mu \mathrm{l}$ formazan solution was added into each well and incubated at $37^{\circ} \mathrm{C}$ for a further $4 \mathrm{~h}$ in order to dissolve the formazan crystals. The absorbance at $570 \mathrm{~nm}$ was then determined using a microplate reader (Multiskan Spectrum; Thermo Fishers Scientific, Inc.).

Transwell migration assay. A 6-well Transwell system (8 $\mu \mathrm{m}$; Corning Incorporated, Corning, NY, USA) was used in the present study to determine cell migration. Following washing with PBS, the cells were suspended in RPMI-1640 cell medium without serum at a density of $5 \times 10^{4}$ cells $/ \mathrm{ml}$ in the upper chambers, and $2 \mathrm{ml}$ of cell suspension was then added to the Transwell plates. RPMI-1640 cell medium with $10 \%$ fetal calf serum $(1 \mathrm{ml})$ was then added to the lower chambers. The plates were incubated at $37^{\circ} \mathrm{C}$ for $24 \mathrm{~h}$, and the upper chamber was 

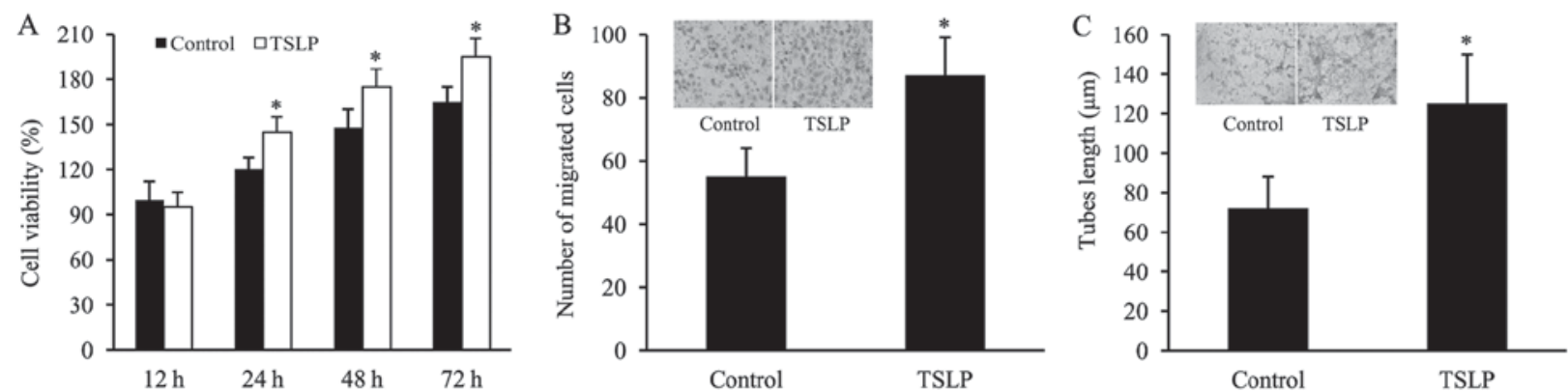

Figure 5. Effect of TSLP on in vitro angiogenesis of HUVECs subjected to OGD. Results are displayed as (A) effect of TSLP on cell proliferation of OGD-treated HUVECs, (B) effect of TSLP on cell migration of OGD-treated HUVECs and (C) effect of TSLP on tube length of OGD-treated HUVECs. $\mathrm{n}=3$. "P<0.05 vs. control. HUVECs, human umbilical vein endothelial cells; OGD, oxygen-glucose deprivation; TSLP, thymic stromal lymphopoietin.

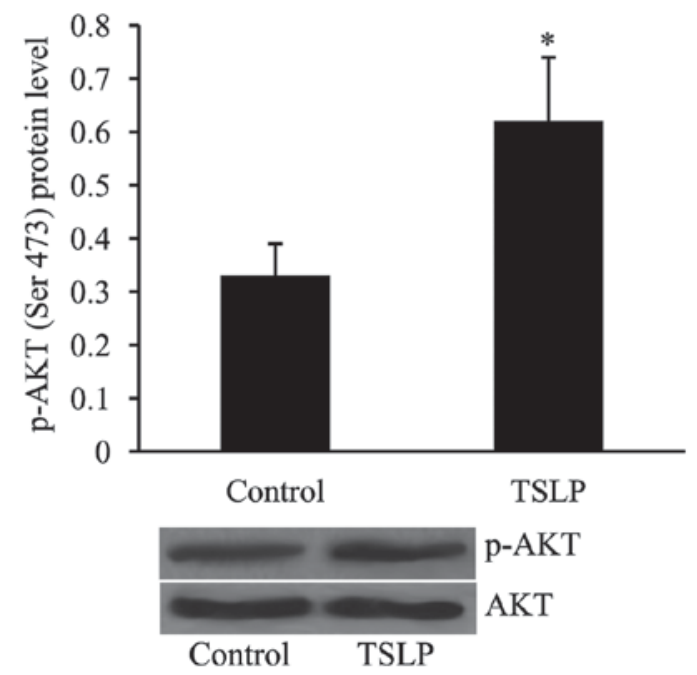

Figure 6. Effect of TSLP $(20 \mathrm{ng} / \mathrm{ml})$ on the phosphatidylinositol 3 kinase pathway in human umbilical vein endothelial cells subjected to OGD, AKT served as the control. $n=3$. ${ }^{*} \mathrm{P}<0.05$ vs. control (cells treated with PBS) TSLP, thymic stromal lymphopoietin; OGD, oxygen-glucose deprivation; AKT, protein kinase B; p-AKT, phosphorylated AKT; TSLP, thymic stromal lymphopoietin.

then fixed in $95 \%$ ethanol at room temperature for $15 \mathrm{~min}$ and stained with $10 \%$ hematoxylin for $15 \mathrm{~min}$ at room temperature. The number of migrated cells was revealed using an Eclipse TS100 microscope (magnification x400; Nikon Corporation, Tokyo, Japan).

Tube formation assay. The BD Matrigel matrix (BD Biosciences, Franklin Lakes, NJ, USA) was thawed overnight on ice at $4^{\circ} \mathrm{C}$, and was subsequently added to pre-chilled 24-well plates and incubated at $37^{\circ} \mathrm{C}$ for $1 \mathrm{~h}$ for solidification. The cells were then digested at a density of $4 \times 10^{5}$ cells $/ \mathrm{ml}$, and $50 \mu \mathrm{l}$ of the cell suspension was then added to each well. The plates were then incubated at $37^{\circ} \mathrm{C}$, and formation of tube structure was observed $8 \mathrm{~h}$ later using a Leica DFC345 FX microscope. Tube lengths for each group were then measured using ImageJ software, version 1.45 (GraphPad Software, Inc., La Jolla, CA, USA), in 10 randomly selected fields.

Statistical analysis. All statistical analyses were performed using SPSS 19.0 (IBM Corp., Armonk, NY, USA), and the data are expressed as the mean \pm standard deviation. Comparisons between two groups were performed using the Student's t test, and one-way analysis of variance followed by Fisher's Least Significant Difference test was used to compare the statistically significant differences between multiple groups. $\mathrm{P}<0.05$ was considered to indicate a statistically significant difference.

\section{Results}

Expression of TSLP and TSLPR is upregulated following $M C A O$. The rat MCAO model was constructed and the expression of TSLP and TSLPR was then examined using ELISA and western blot analyses at 6,12,24 and $72 \mathrm{~h}$ time intervals following MCAO. As presented in Fig. 1, compared with the sham at $6 \mathrm{~h}$, the expression levels of both TSLP and TSLPR were significantly increased at 12, 24 and $72 \mathrm{~h}$ time intervals following MCAO.

TSLP promotes the expression of VEGFA and Ang-2 following MCAO. In order to investigate whether TSLP affects angiogenesis following MCAO, the rats in the MCAO group were injected with TSLP $(10 \mu \mathrm{g})$, and the expression levels of VEGFA and Ang-2 in the cerebral infarct area were determined by western blot analysis. It was revealed that compared with the sham, the expression levels of both VEGFA and Ang-2 were significantly upregulated following MCAO. VEGFA and Ang-2 expression levels were further increased in the MCAO rats injected with TSLP (Fig. 2).

TSLP activates PI3K/AKT signaling pathway following $M C A O$. In order to investigate whether or not the PI3K/AKT pathway could be activated by TSLP following MCAO, p-AKT was investigated using western blot. It was subsequently revealed that the level of p-AKT was significantly increased in the MCAO group compared with the control group. Additionally, $10 \mu \mathrm{g}$ TSLP injection caused further activation of the PI3K/AKT signaling pathway in the MCAO rats (Fig. 3).

Expression of TSLP and TSLPR is upregulated in HUVECs subjected to OGD. In order to create the in vitro MCAO model, the HUVECs were exposed to OGD, and the expression levels of both TSLP and TSLPR were subsequently examined using ELISA and western blot analyses, respectively. As demonstrated in Fig. 4, the expression levels of TSLP and TSLPR in OGD-treated HUVECs, in comparison with the cells cultured under normal conditions, were significantly increased. 

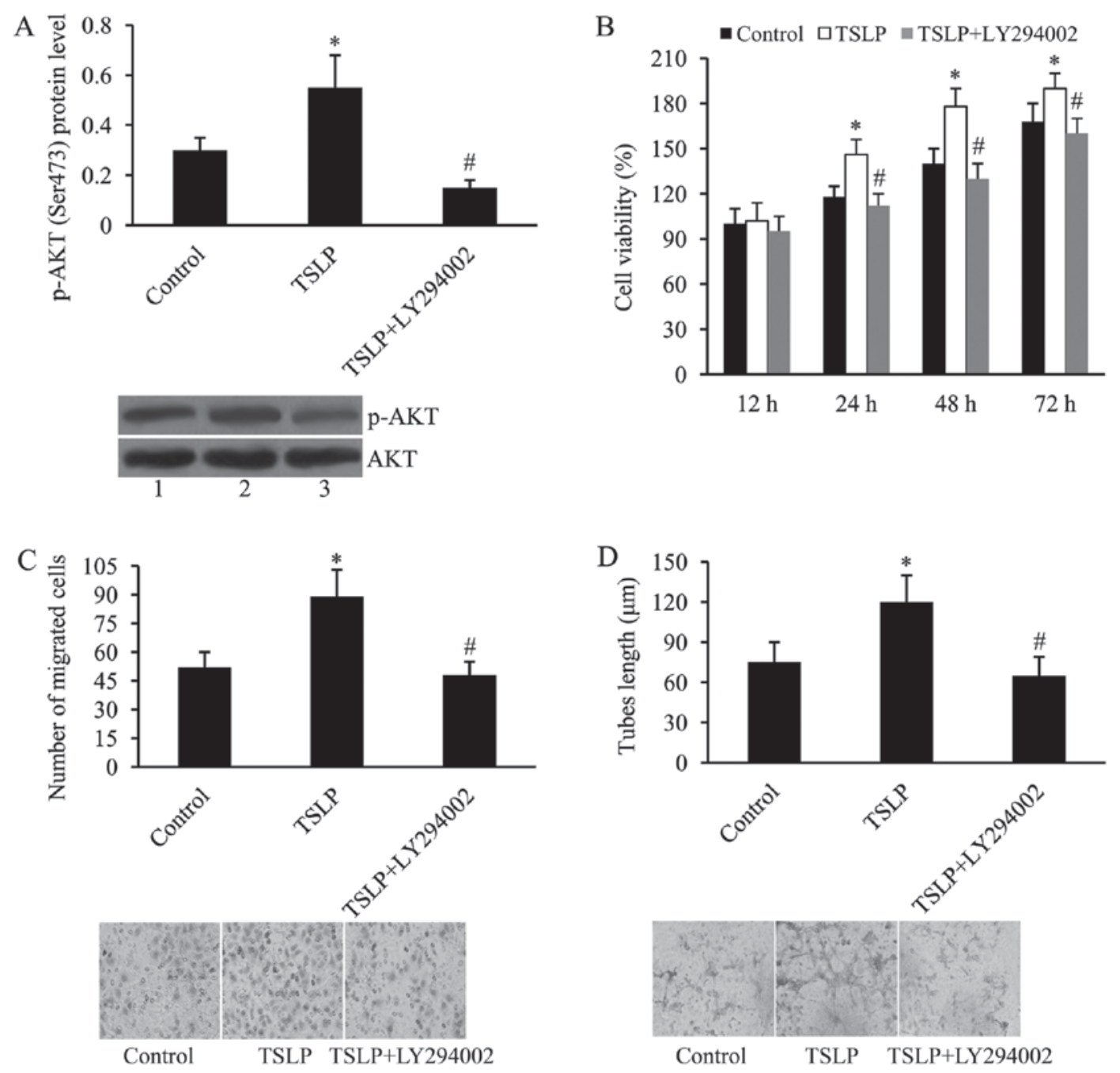

Figure 7. PI3K inhibition attenuates the effect of TSLP on in vitro angiogenesis of HUVECs subjected to OGD. (A) LY294002 attenuates TSLP-induced PI3K/AKT activation in OGD-treated HUVECs. AKT served as the control. Lane 1, control; lane 2, TSLP; lane 3, TSLP + LY294002; (B) LY294002 attenuates TSLP-induced cell proliferation of OGD-treated HUVECs; (C) LY294002 attenuates TSLP-induced cell migration of OGD-treated HUVECs; and (D) LY294002 attenuates TSLP-induced tubes length of OGD-treated HUVECs. $\mathrm{n}=3$. ${ }^{*} \mathrm{P}<0.05$ vs. control; ${ }^{\#} \mathrm{P}<0.05$ vs. TSLP group. TSLP, thymic stromal lymphopoietin; PI3K, phosphatidylinositol 3 kinase; HUVECs, human umbilical vein endothelial cells; OGD, oxygen-glucose deprivation; AKT, protein kinase B; p-AKT, phosphorylated AKT; LY294002, PI3K inhibitor.

TSLP promotes the in vitro angiogenesis of HUVECs subjected to OGD. The HUVECs subjected to OGD were treated with TSLP, and then cell viability, cell migration and tube formation were examined in order to determine the effect of TSLP on the angiogenic capacity of OGD-treated HUVECs. It was observed that cell viability was significantly increased following TSLP treatment (Fig. 5A). Furthermore, in the TSLP group, the number of migrated cells was significantly increased in comparison with the control (Fig. 5B). Additionally, TSLP treatment led to an increase in the tube lengths of OGD-treated HUVECs compared with the control treatment (Fig. 5C).

TSLP activates PI3K/AKT signaling pathway in HUVECs subjected to $O G D$. The level of p-AKT was examined in OGD-treated HUVECs in order to determine whether or not the PI3K/AKT pathway is involved in mediating the effect of TSLP on angiogenesis in vitro. As revealed in Fig. 6, the level of p-AKT was significantly increased in OGD-treated HUVECs following TSLP treatment compared with the control group.
PI3K inhibition attenuates the effect of TSLP on in vitro angiogenesis of HUVECs subjected to OGD. LY294002, a PI3K inhibitor, was used to determine whether the PI3K/AKT signaling pathway mediates the effect of TSLP on in vitro angiogenesis of OGD-treated HUVECs. As demonstrated by western blot analysis, LY294002 inhibited the expression of p-AKT induced by TSLP in OGD-treated HUVECs (Fig. 7A).

Additionally, cell viability was investigated using MTT. It was subsequently revealed that the effect of TSLP on cell proliferation was reversed by the addition of LY294002 (Fig. 7B). In addition, TSLP-induced cell migration was suppressed by LY294002 (Fig. 7C). Tube lengths were also assessed using the tube formation assay. As demonstrated by Fig. 7D, the effect of TSLP on tube formation of OGD-treated HUVECs was attenuated by the addition of LY294002.

\section{Discussion}

OGD and MCAO are in vitro and in vivo cerebral ischemia models (23-26). HUVECs are commonly used as a laboratory 
model system for the study of angiogenesis. Previous studies have used OGD-treated HUVECs to investigate stroke (27-29). In this study, an in vitro cerebral ischemia model was established by exposing HUVECs to OGD. The present study demonstrated that TSLP/TSLPR promote angiogenesis following ischemic stroke in both animal experiments and cultured cell experiments. Furthermore, it was confirmed that TSLP/TSLPR may exert effects on angiogenesis via the PI3K/AKT signaling pathway.

Several studies have previously reported that TSLP is involved in the pathogenesis of atherosclerosis, diabetes, obesity and asthma (30-32). Recently, Kitic et al (33) reported that TSLP is also expressed in the central nervous system, and that microglial cells express TSLPR. The expression of TSLP in the central nervous system varies among different pathological conditions (33). However, whether TSLP/TSLPR are involved in the pathogenesis of ischemic stroke remains unknown. In the present study, a rat MCAO model was established, and it was revealed that the expression levels of TSLP and TSLPR were significantly increased in the infarct area between 12 and $72 \mathrm{~h}$ following MCAO. An in vitro MCAO model was constructed by exposing the HUVECs to OGD, and it was revealed that the expression levels of TSLP and TSLPR were significantly increased in HUVECs subjected to OGD compared with those cultured under normal conditions. These results suggest that TSLP/TSLPR may be involved in the pathogenesis of ischemic stroke.

Angiogenesis is a key neurorestorative event in response to ischemia (8). Following ischemic stroke, angiogenesis occurs in the ischemic boundary zone and improves neurological function $(34,35)$. VEGFA is an essential molecule in both physiological and pathological angiogenesis. This growth factor induces proliferation, differentiation and migration of vascular endothelial cells. Following ischemic stroke, elevated levels of VEGFA promote capillary formation and increase blood flow to the area surrounding the infarction (36). Ang-2 may facilitate endothelial cell migration and proliferation in co-ordination with VEGFA, thus acting as an angiogenic signal (37). A previous study reported that TSLP stimulates the proliferation and activation of HUVECs, and upregulates the expression of angiogenesis-associated molecules, CD62E and CD105 (21). Consistent with these findings, the in vitro results of the present study demonstrated that TSLP treatment promoted cell proliferation and migration, and induced tube formation of OGD-treated HUVECs. In addition, the in vivo results revealed that the expression levels of angiogenic molecules, VEGFA and Ang-2 were increased following MCAO. TSLP injection further upregulated VEGFA and Ang-2 expression in the infarct area. These results suggest that TSLP promotes angiogenesis following ischemic stroke in both in vivo and in vitro conditions.

The PI3K/AKT signaling pathway participates in various cellular activities, such as cell proliferation, apoptosis, differentiation and inflammatory responses. Additionally, the activation of the PI3K/AKT signaling pathway has been revealed to be implicated in the occurrence and development of angiogenesis $(38,39)$. Previous evidence has demonstrated that TSLP/TSLPR functions via activation of the PI3K/AKT pathway in order to induce platelet activation (40). In the present study, it was investigated whether the PI3K/AKT signaling pathway mediates the effects of TSLP/TSLPR on angiogenesis following ischemic stroke. Consistent with the aforementioned study (40), TSLP was demonstrated to activate the PI3K/AKT signaling pathway in OGD-treated HUVECs. LY294002, a PI3K inhibitor, was used in this study to suppress the PI3K/AKT signaling pathway. Subsequently, the effects of TSLP on in vitro angiogenesis of OGD-treated HUVECs were attenuated by LY294002.

In conclusion, the findings of this study suggest a novel mechanism underlying the role of TSLP/TSLPR in angiogenesis following ischemic stroke. This study, to the best of our knowledge, is the first to demonstrate that TSLP/TSLPR promote angiogenesis following ischemic stroke in vivo and in vitro, and that these effects are mediated, at least partially, via the activation of the PI3K/AKT signaling pathway. Therefore, TSLP/TSLPR may be potential therapeutic targets for ischemic stroke treatment. Further studies are required to confirm the effects of TSLP/TSLPR on angiogenesis in clinical stroke patients, examine the expression of TSLP/TSLPR in brain tissues and investigate angiogenesis using imaging tests in infarct areas following TSLP/TSLPR treatment.

\section{References}

1. GBD 2013 Mortality and Causes of Death Collaborators: Global, regional, and national age-sex specific all-cause and cause-specific mortality for 240 causes of death, 1990-2013: A systematic analysis for the global burden of disease study 2013. Lancet 385: 117-171, 2015.

2. Feigin VL, Forouzanfar MH, Krishnamurthi R, Mensah GA, Connor M, Bennett DA, Moran AE, Sacco RL, Anderson L, Truelsen T, et al: Global and regional burden of stroke during 1990-2010: Findings from the global burden of disease study 2010. Lancet 383: 245-254, 2014.

3. Wang WZ: Neurology. 4th edition. People's Medical Publishing House, Beijing, pp130, 2001.

4. Bang OY, Saver JL, Buck BH, Alger JR, Starkman S, Ovbiagele B, Kim D, Jahan R, Duckwiler GR, Yoon SR, et al: Impact of collateral flow on tissue fate in acute ischaemic stroke. J Neurol Neurosurg Psychiatry 79: 625-629, 2008.

5. Miteff F, Levi CR, Bateman GA, Spratt N, McElduff P and Parsons MW: The independent predictive utility of computed tomography angiographic collateral status in acute ischaemic stroke. Brain 132: 2231-2238, 2009.

6. Liebeskind DS, Cotsonis GA, Saver JL, Lynn MJ, Turan TN, Cloft HJ and Chimowitz MI; Warfarin-Aspirin Symptomatic Intracranial Disease (WASID) Investigators: Collaterals dramatically alter stroke risk in intracranial atherosclerosis. Ann Neurol 69: 963-974, 2011.

7. Velazquez OC, Snyder R, Liu ZJ, Fairman RM and Herlyn M: Fibroblast-dependent differentiation of human microvaseular endothelial cells into capillary-like 3-dimensional networks. FASEB J 16: 1316-1318, 2002.

8. Arai K, Jin G, Navaratna D and Lo EH: Brain angiogenesis in developmental and pathological processes: Neurovascular injury and angiogenic recovery after stroke. FEBS J 276: 4644-4652, 2009.

9. Lin J, Chang W, Dong J, Zhang F, Mohabeer N, Kushwaha KK, Wang L, Su Y, Fang $\mathrm{H}$ and Li D: Thymic stromal lymphopoietin over-expressed in human atherosclerosis: Potential role in Th17 differentiation. Cell Physiol Biochem 31: 305-318, 2013.

10. Zhao H, Li M, Wang L, Su Y, Fang H, Lin J, Mohabeer N and Li D: Angiotensin II induces TSLP via an AT1 receptor/NF-KappaB pathway, promoting Th17 differentiation. Cell Physiol Biochem 30: 1383-1397, 2012.

11. Yu K, Zhu P, Dong Q, Zhong Y, Zhu Z, Lin Y, Huang Y, Meng K, Ji Q, Yi G, et al: Thymic stromal lymphopoietin attenuates the development of atherosclerosis in ApoE-/- mice. J Am Heart Assoc 2: e000391, 2013. 
12. Blagoev M, Nielsen MM, Angrist M, Chakravarti A and Pandey A: Cloning of rat thymic stromal lymphopoietin receptor (TSLPR) and characterization of genomic structure of murine Tslpr gene. Gene 284: 161-168, 2002.

13. Pandey A, Ozaki K, Baumann H, Levin SD, Puel A, Farr AG, Ziegler SF, Leonard WJ and Lodish HF: Cloning of a receptor subunit required for signaling by thymic stromal lymphopoietin. Nat Immunol 1: 59-64, 2000.

14. Zhang W, Wang J, Wang Q, Chen G, Zhang J, Chen T, Wan T, Zhang Y and Cao X: Identification of a novel type I cytokine receptor CRL2 preferentially expressed by human dendritic cells and activated monocytes. Biochem Biophys Res Commun 281: 878-883, 2001

15. Tonozuka Y, Fujio K, Sugiyama T, Nosaka T, Hirai M and Kitamura T: Molecular cloning of a human novel type I cytokine receptor related to delta1/TSLPR. Cytogenet Cell Genet 93: 23-25, 2001.

16. Reche PA, Soumelis V, Gorman DM, Clifford T, Liu MR, Travis M, Zurawski SM, Johnston J, Liu YJ, Spits H, et al: Human thymic stromal lymphopoietin preferentially stimulates myeloid cells. J Immunol 167: 336-343, 2001.

17. Soumelis V, Reche PA, Kanzler H, Yuan W, Edward G, Homey B, Gilliet M, Ho S, Antonenko S, Lauerma A, et al: Human epithelial cells trigger dendritic cell mediated allergic inflammation by producing TSLP. Nat Immunol 3: 673-680, 2002.

18. He R and Geha RS: Thymic stromal lymphopoietin. Ann N Y Acad Sci 1183: 13-24, 2010.

19. Ziegler SF and Artis D: Sensing the outside world: TSLP regulates barrier immunity. Nat Immunol 11: 289-293, 2010.

20. Ma P, Bian F, Wang Z, Zheng X, Chotikavanich S, Pflugfelder SC and Li DQ: Human corneal epithelium-derived thymic stromal lymphopoietin links the innate and adaptive immune responses via TLRs and Th2 cytokines. Invest Ophthalmol Vis Sci 50 2702-2709, 2009.

21. Xie F, Meng YH, Liu LB, Chang KK, Li H, Li MQ and Li DJ: Cervical carcinoma cells stimulate the angiogenesis through TSLP promoting growth and activation of vascular endothelia cells. Am J Reprod Immunol 70: 69-79, 2013.

22. Longa EZ, Weinstein PR, Carlson S and Cummins R: Reversible middle cerebral artery occlusion without craniectomy in rats. Stroke 20: 84-91, 1989.

23. Goldberg MP and Choi DW: Combined oxygen and glucose deprivation in cortical cell culture: Calcium-dependent and calcium-independent mechanisms of neuronal injury. J Neurosci 13: 3510-3524, 1993.

24. Brint S, Jacewicz M, Kiessling M, Tanabe J and Pulsinelli W: Focal brain ischemia in the rat: Methods for reproducible neocortical infarction using tandem occlusion of the distal middle cerebral and ipsilateral common carotid arteries. J Cereb Blood Flow Metab 8: 474-485, 1988.

25. Tamura A, Graham DI, McCulloch J and Teasdale GM: Focal cerebral ischaemia in the rat: 1 . Description of technique and early neuropathological consequences following middle cerebral artery occlusion. J Cereb Blood Flow Metab 1: 53-60, 1981.

26. Tamura A, Graham DI, McCulloch J and Teasdale GM: Focal cerebral ischaemia in the rat: 2 . Regional cerebral blood flow determined by [14C]iodoantipyrine autoradiography following middle cerebral artery occlusion. J Cereb Blood Flow Metab 1: 61-69, 1981.
27. Li L, Zhang B, Tao Y, Wang Y, Wei H, Zhao J, Huang R and Pei Z: DL-3-n-butylphthalide protects endothelial cells against oxidative/nitrosative stress, mitochondrial damage and subsequent cell death after oxygen glucose deprivation in vitro. Brain Res 1290: 91-101, 2009.

28. Urbanek T, Kuczmik W, Basta-Kaim A and Gabryel B: Rapamycin induces of protective autophagy in vascular endothelial cells exposed to oxygen-glucose deprivation. Brain Res 1553: 1-11, 2014.

29. Dong W, Xiao S, Cheng M, Ye X and Zheng G: Minocycline induces protective autophagy in vascular endothelial cells exposed to an in vitro model of ischemia/reperfusion-induced injury. Biomed Rep 4: 173-177, 2016.

30. Ying S, O'Connor B, Ratoff J, Meng Q, Mallett K, Cousins D, Robinson D, Zhang G, Zhao J, Lee TH and Corrigan C: Thymic stromal lymphopoietin expression is increased in asthmatic airways and correlates with expression of Th2-attracting chemokines and disease severity. J Immunol 174: 8183-8190, 2005.

31. Besin G, Gaudreau S, Ménard M, Guindi C, Dupuis G and Amrani A: Thymic stromal lymphopoietin and thymic stromal lymphopoietin-conditioned dendritic cells induce regulatory T-cell differentiation and protection of NOD mice against diabetes. Diabetes 57: 2107-2117, 2008.

32. Turcot V, Bouchard L, Faucher G, Garneau V, Tchernof A, Deshaies Y, Pérusse L, Marceau S, Biron S, Lescelleur O, et al: Thymic stromal lymphopoietin: An immune cytokine gene associated with the metabolic syndrome and blood pressure in severe obesity. Clin Sci(Lond) 123: 99-109, 2012.

33. Kitic M, Wimmer I, Adzemovic M, Kögl N, Rudel A, Lassmann $\mathrm{H}$ and Bradl $\mathrm{M}$ : Thymic stromal lymphopoietin is expressed in the intact central nervous system and upregulated in the myelin-degenerative central nervous system. Glia 62: 1066-1074, 2014

34. Liu J, Wang Y, Akamatsu Y, Lee CC, Stetler RA, Lawton MT and Yang GY: Vascular remodeling after ischemic stroke: Mechanisms and therapeutic potentials. Prog Neurobiol 115: 138-156, 2014.

35. Krupinski J, Kaluza J, Kumar P, Kumar S and Wang JM: Role of angiogenesis in patients with cerebral ischemic stroke. Stroke 25: 1794-1798, 1994

36. Risau W: Mechanisms of angiogenesis. Nature 386: 671-674, 1997.

37. Biel NM and Siemann DW: Targeting the Angiopoietin-2/Tie-2 axis in conjunction with VEGF signal interference. Cancer Lett 380: 525-533, 2016

38. Everaert BR, Van Craenenbroeck EM, Hoymans VY, Haine SE, Van Nassauw L, Conraads VM, Timmermans JP and Vrints CJ: Current perspective of pathophysiological and interventional effects on endothelial progenitor cell biology: Focus on PI3K/AKT/eNOS pathway. Int J Cardiol 144: 350-366, 2010.

39. Tokunaga E, Oki E, Egashira A, Sadanaga N, Morita M, Kakeji Y and Maehara Y: Deregulation of the Akt pathway in human cancer. Curr Cancer Drug Targets 8: 27-36, 2008.

40. Wang B, Peng Y, Dong J, Lin J, Wu C, Su Y, Fang H, Wang L, Huang K and Li D: Human platelets express functional thymic stromal lymphopoietin receptors: A potential role in platelet activation in acute coronary syndrome. Cell Physiol Biochem 32: 1741-1750, 2013. 